\title{
Biosynthesis of Yttrium oxide nanoparticles using Acalypha indica leaf extract
}

\author{
S K KANNAN and M SUNDRARAJAN* \\ Advanced Green Chemistry Lab, Department of Industrial Chemistry, School of Chemical Sciences, Alagappa University, \\ Karaikudi 630 003, Tamil Nadu, India
}

MS received 7 July 2014; accepted 3 February 2015

\begin{abstract}
In this study, the synthesis of Yttrium oxide $\left(\mathrm{Y}_{2} \mathrm{O}_{3}\right)$ nanoparticles was carried out from Acalypha indica leaf extract. The synthesized nanoparticles were characterized by using X-ray diffraction, scanning electron microscope, energy-dispersive $\mathrm{X}$-ray spectrometer and transmission electron microscope for structural confirmation. The studies clearly indicate that the synthesized $\mathrm{Y}_{2} \mathrm{O}_{3}$ nanoparticle is a crystalline material with a particle size from 23 to $66 \mathrm{~nm}$. Further analysis was carried out by Fourier transform infrared spectroscopy, to provide the evidence for the presence of $\mathrm{Y}-\mathrm{O}-\mathrm{Y}$ and $\mathrm{O}-\mathrm{Y}-\mathrm{O}$ stretchings in the synthesized $\mathrm{Y}_{2} \mathrm{O}_{3}$ nanoparticles. Thermogravimetric and differential scanning calorimetry analyses gave the thermal stability of $\mathrm{Y}_{2} \mathrm{O}_{3}$ nanoparticles. The results of the antibacterial studies conducted by using the synthesized $\mathrm{Y}_{2} \mathrm{O}_{3}$ revealed an increasing rate of antibacterial behaviour with pathogens.
\end{abstract}

Keywords. Yttrium oxide; biosynthesis; nanostructure; Acalypha indica; antibacterial activity.

\section{Introduction}

Nanosized metal oxides, in a variety of morphologies (such as particles, spheres, rods and sheets) have attracted a great deal of attention. This is owing mainly to their physico-chemical properties associated with their technological application. Synthesis of nanosized material is one of the major challenges in the development of advanced functional materials because they exhibit unique properties conferred by particles of very small dimension in contrast to the corresponding bulk material. ${ }^{1-3}$ Interest in nanoparticles for biological and medical applications continues to grow. Nanoparticles find use as delivery vehicles for drugs, ${ }^{4,5}$ genes $^{6,7}$ and growth factor ${ }^{8}$ as well as cellular labels for imaging both in vitro and in vivo. ${ }^{9-11}$ Nanoparticles are also being studied for the use in photodynamic therapy ${ }^{12}$ and hyperthermia therapy for tumour, ${ }^{13}$ with the goal of clinical application.

Nowadays biosynthesis plays a vital role in the synthesis of metal and metal oxide nanoparticles. It eliminates toxic chemicals which are formed as by-products in certain chemical reactions and removes the organic solvent in the synthetic protocol. Green synthesis offers improvement over synthetic, chemical or microbiological methods as it is cost effective, environmental friendly and can easily be scaled up for large-scale synthesis. Although biosynthesis of metal and metal oxide nanoparticles by plants such as Alfalfa,${ }^{14,15}$ Aloe

\footnotetext{
*Author for correspondence (sundrarajan@yahoo.com)
}

vera,${ }^{16}$ Cinnamomum camphora, ${ }^{17}$ Emblica officianalis, ${ }^{18}$ have been reported, the potential plants as biological materials for the synthesis of nanoparticles is yet to be fully explored.

Yttrium oxide $\left(\mathrm{Y}_{2} \mathrm{O}_{3}\right)$, as an important member among rare earth compounds, has been actively studied in the recent years. It is one of the most promising elements for the fabrication of optoelectronic devices and chemical catalysis. $\mathrm{Y}_{2} \mathrm{O}_{3}$ is a well-known material for its characteristics of high dielectric constant and good thermal stability in a powder state. ${ }^{19} \mathrm{Y}_{2} \mathrm{O}_{3}$ can be used as high efficient additives and functional composite materials like yttria-stabilized zirconia films. ${ }^{20,21}$ In addition to that, it is widely used as a host material for various rare earth dopants and is of interest for potential applications in biological imaging as well as photodynamic therapy. ${ }^{22,23}$

The aim of this work is to study the processes taking place in the precipitation of yttrium hydroxides from nitrate solutions by using Acalypha indica leaf extracts as a precipitant, the thermal decomposition of precipitates with the production of $\mathrm{Y}_{2} \mathrm{O}_{3}$ and the evolution of particle ensembles in the processes of thermal processing. The synthesized pure $\mathrm{Y}_{2} \mathrm{O}_{3}$ nanoparticles were characterized by X-ray diffraction (XRD), scanning electron microscope (SEM), transmission electron microscope (TEM), enery-dispersive $\mathrm{X}$-ray (EDX) spectrometer, Fourier transform infrared (FTIR) spectroscopy and thermogravimetric analysis (TGA)differential scanning calorimetry (DSC) analyses. Further the $\mathrm{Y}_{2} \mathrm{O}_{3}$ nanoparticle was tested for its antibacterial activity with human pathogens. 


\section{Experiment}

\subsection{Material}

Yttrium nitrate hexahydrate $\left[\mathrm{Y}\left(\mathrm{NO}_{3}\right)_{3} \cdot 6 \mathrm{H}_{2} \mathrm{O}\right]$ purchased from Alfa Aesar was directly used without further purification. The leaves of $A$. indica were collected in the Alagappa University Campus, India, washed thoroughly with double distilled water and dried for a week at room temperature.

\subsection{Preparation of plant extract}

The dried and finely cut leaves (20 g) were boiled in a 250 $\mathrm{ml}$ Erlenmeyer flask with $100 \mathrm{ml}$ of double distilled water for $30 \mathrm{~min}$. Then the extract was filtered through ordinary filter paper and through Whatman No. 1 filter paper. The filtrate was collected and it was kept in a refrigerator at $4^{\circ} \mathrm{C}$ for further experiments.

\subsection{Synthesis of $\mathrm{Y}_{2} \mathrm{O}_{3}$ nanoparticle}

Aqueous solution of $0.1 \mathrm{M}$ yttrium nitrate hexahydrate $\left[\mathrm{Y}\left(\mathrm{NO}_{3}\right)_{3} \cdot 6 \mathrm{H}_{2} \mathrm{O}\right]$ was used for the synthesis of $\mathrm{Y}_{2} \mathrm{O}_{3}$ nanoparticles. Briefly, $10 \mathrm{ml}$ of $A$. indica leaf extract was added to $50 \mathrm{ml}$ of $0.1 \mathrm{M} \mathrm{Y}\left(\mathrm{NO}_{3}\right)_{3} \cdot 6 \mathrm{H}_{2} \mathrm{O}$ in a $250 \mathrm{ml}$ Erlenmeyer flask and stirred at $80^{\circ} \mathrm{C}$ for $2 \mathrm{~h}$. The particle formed after adequate time of stirring was collected by centrifugation at 10,000 rpm for $10 \mathrm{~min}$. The centrifuged particles were washed with deionized water and again subjected to centrifugation at $1500 \mathrm{rpm}$ for $30 \mathrm{~min}$. The centrifuged sample, dried in an air oven, was powdered using mortar and pestle. This powdered sample was calcined in a muffle furnace at $500^{\circ} \mathrm{C}$ to obtain $\mathrm{Y}_{2} \mathrm{O}_{3}$ nanoparticles. ${ }^{24}$

\subsection{Characterization}

SEM images were obtained using HITACHI Model S-3000H at various magnifications to study the surface morphology of $\mathrm{Y}_{2} \mathrm{O}_{3}$ nanoparticles. XRD data sets were recorded at room temperature on a PANalytical X'PERT PRO system in Bragg-Brentano geometry using $\mathrm{CuK} \alpha 1$ (1.540 ̊) radiation. The powder diffraction covered the $10^{\circ}<2 \theta>40^{\circ}$ range with $0.0170^{\circ}$ steps. FT-IR spectra were obtained using BRUKER Optik GmbH FTIR spectrometer model TENSOR 27 in the diffuse reflection mode. The TEM images were recorded by using PHILIPS CM 200, operating voltage $20-200 \mathrm{kV}$ with resolution range at $2.4 \AA$. TGA-DSC reports were collected by using TGA-DSC Perkin Elmer Instruments under nitrogen flow condition.

\subsection{Antibacterial activity study}

2.5a Disc diffusion method: Escherichia coli (E. coli), Pseudomonas aeruginosa (P. aeruginosa), Serratia marcescens (S. marcescens) and Staphylococcus aureus (S. aureus) cultures were used for this study as reference strains used for antimicrobial susceptibility testing by the Kirby-Bauer diffusion method. The bacterial suspension was applied uniformly on the surface of a Muller Hinton agar (MHA) plate in the concentration range of $10^{5}-10^{6} \mathrm{CFU} \mathrm{ml}^{-1}$ before placing $\mathrm{Y}_{2} \mathrm{O}_{3}$ nanoparticle laden disk. The strains were cultured on nutrient agar (Himedia, India) and incubated aerobically at $35^{\circ} \mathrm{C}$ overnight.

2.5b Turbidimetric method: The antibacterial activity of the $\mathrm{Y}_{2} \mathrm{O}_{3}$ nanoparticles was justified by an alternative route like the turbidimetric method. In this method, the antibacterial behaviour of $\mathrm{Y}_{2} \mathrm{O}_{3}$ against $E$. coli, P. aeruginosa, $S$. marcescens and $S$. aureus in Luria Bertani broth (LB). The 24-h-old bacterial cultures were inoculated into LB broth supplemented with various concentrations $(10,15,25,50,75$ and $100 \mu \mathrm{l}$ ) of $\mathrm{Y}_{2} \mathrm{O}_{3}$ nanoparticles. $\mathrm{Y}_{2} \mathrm{O}_{3}$-free LB broth was used as a control. The broth containing conical flasks was incubated at room temperature under stirring for $24 \mathrm{~h}$ and the vulnerability of the tested organisms was observed by taking optical density at $600 \mathrm{~nm}$ for various time intervals.

\section{Results and discussion}

XRD has been used to characterize the structure of $\mathrm{Y}_{2} \mathrm{O}_{3}$ nanoparticle. Figure 1 shows a typical diffraction pattern of this material. This could clearly demonstrate that, the synthesized $\mathrm{Y}_{2} \mathrm{O}_{3}$ nanoparticle is identical and could be indexed to the standard $\mathrm{Y}_{2} \mathrm{O}_{3}$ with body centered cubic structure (JCPDS no: 89-5591). The lattice parameter calculated from (222) Bragg's reflection of the pure $\mathrm{Y}_{2} \mathrm{O}_{3}$ nanoparticle sample is $10.62 \AA$ which matches well with the lattice parameter of bulk $\mathrm{Y}_{2} \mathrm{O}_{3}(a=10.60)$. Some minor peaks appeared in an XRD data due to traces of other impurities were observed in the XRD pattern after calcined at $500^{\circ} \mathrm{C}$ in the air.

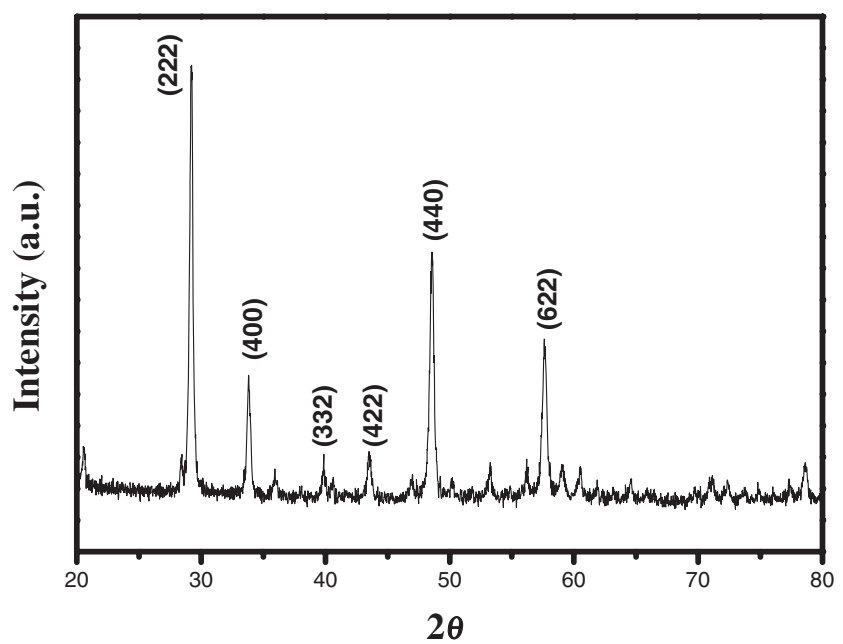

Figure 1. XRD pattern of the synthesized $\mathrm{Y}_{2} \mathrm{O}_{3}$ nanoparticles using Acalypha indica leaf extract. 
The crystallite size of $\mathrm{Y}_{2} \mathrm{O}_{3}$ nanoparticle was estimated from Scherrer's equation as $33.5 \mathrm{~nm}$.

The FT-IR spectrum of $\mathrm{Y}_{2} \mathrm{O}_{3}$ made from $\mathrm{KBr}$ pellet is shown in figure 2. There is an absorption peak at 3393, $1607,1384,1175,1072,1010,881,578$ and $459 \mathrm{~cm}^{-1}$. The peak at $3393 \mathrm{~cm}^{-1}$ corresponds to stretching vibration of $\mathrm{O}-\mathrm{H}$ bonds in $\mathrm{H}_{2} \mathrm{O}$ molecules and the band at $1607 \mathrm{~cm}^{-1}$ could be attributed to in-plane and out-of-plane bending of $\mathrm{O}-\mathrm{H}$ bonds present in the adsorbed water molecule. The peaks at 1175,1072 and $1010 \mathrm{~cm}^{-1}$ are the characteristic asymmetric stretching of $\mathrm{Y}-\mathrm{O}-\mathrm{Y}$ present in the nanostructure. The peak at $881 \mathrm{~cm}^{-1}$ is responsible for the presence of trace of $\mathrm{Y}-\mathrm{OH}$. The intense peak at $578 \mathrm{~cm}^{-1}$ corresponds to the anti-symmetric $\mathrm{Y}-\mathrm{O}-\mathrm{Y}$ stretching mode of the surface-bridging oxide. The peak at $459 \mathrm{~cm}^{-1}$ corresponds to symmetric stretching $\mathrm{O}-\mathrm{Y}-\mathrm{O}$ linkage present in $\mathrm{Y}_{2} \mathrm{O}_{3}$ nanoparticles.

The morphology of the synthesized $\mathrm{Y}_{2} \mathrm{O}_{3}$ was examined by SEM and the images are presented in figure 3 . It is clear from the figures that a non-defined morphology of the agglomerated particles is seen and the particles could not be resolved even at high magnification. This is due to the high surface energy of nanoparticles there tendency to form agglomerates are quite strong. Upon contact the primary particles of agglomerate form bonds, which can be

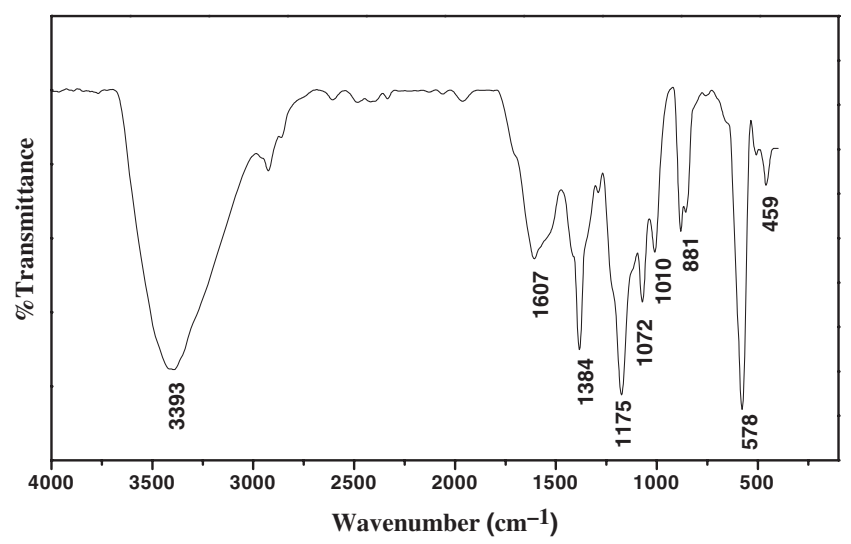

Figure 2. FT-IR spectra of the synthesized $\mathrm{Y}_{2} \mathrm{O}_{3}$ nanoparticles using Acalypha indica leaf extract.
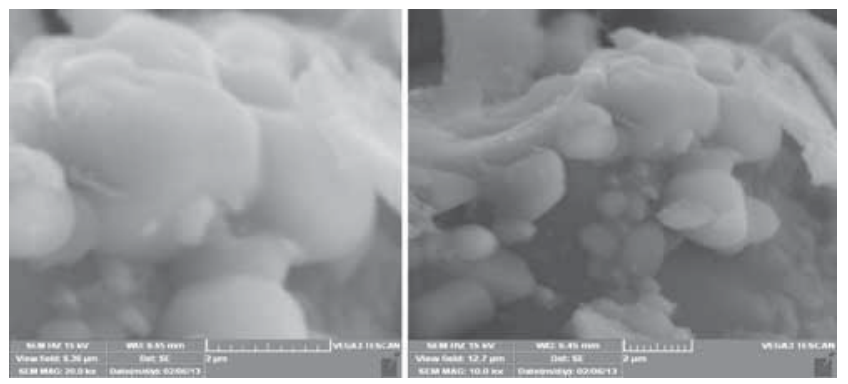

Figure 3. SEM micrograph of the synthesized $\mathrm{Y}_{2} \mathrm{O}_{3}$ nanoparticles using Acalypha indica leaf extract. of different nature. Sintering and individual particle adsorption from the surrounding atmosphere can lead to solid state necks.

Analysis through EDX spectrometer has confirmed the presence of elemental yttrium and the oxygen signal of the $\mathrm{Y}_{2} \mathrm{O}_{3}$ nanoparticles figure 4 . The vertical axis displays the number of X-ray counts while the horizontal axis displays energy in $\mathrm{keV}$. Identification lines for the major emission energies of yttrium and oxygen are displayed and these correspond to peaks in the spectrum, thus giving confidence that yttrium and oxygen has been correctly identified.

A more detailed structural analysis was performed by TEM analysis. A global view of the $\mathrm{Y}_{2} \mathrm{O}_{3}$ nanoparticle at lower magnification is depicted in figure 5. The morphology of the $\mathrm{Y}_{2} \mathrm{O}_{3}$ nanoparticles was ununiformed with distributed elliptically spherical particles with various sizes ranging from 23 to $64 \mathrm{~nm}$. This is because the nanoparticles are agglomerated and the necking between particles examined to determine the particle are sintered together. If the particles are sintered, the diameter of the particle is measured at a fixed angle for all particles in the image. Most of the nanoparticles were well arranged although some of them are partially aggregated. However, TEM analysis illustrates sheet- and spherical-like particles of nearly uniform size. However, agglomeration of particles is also evident from the TEM pictures.

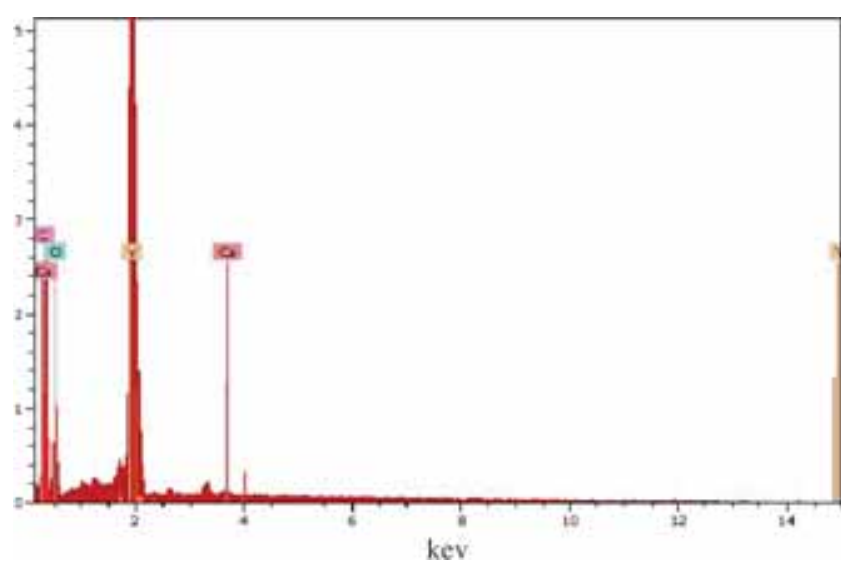

Figure 4. EDX spectrum of the synthesized $\mathrm{Y}_{2} \mathrm{O}_{3}$ nanoparticles using Acalypha indica leaf extract.

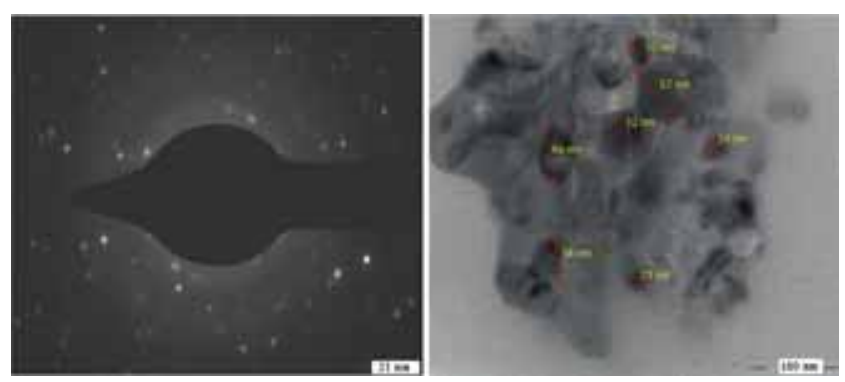

Figure 5. TEM images of the synthesized $\mathrm{Y}_{2} \mathrm{O}_{3}$ nanoparticles using Acalypha indica leaf extract. 


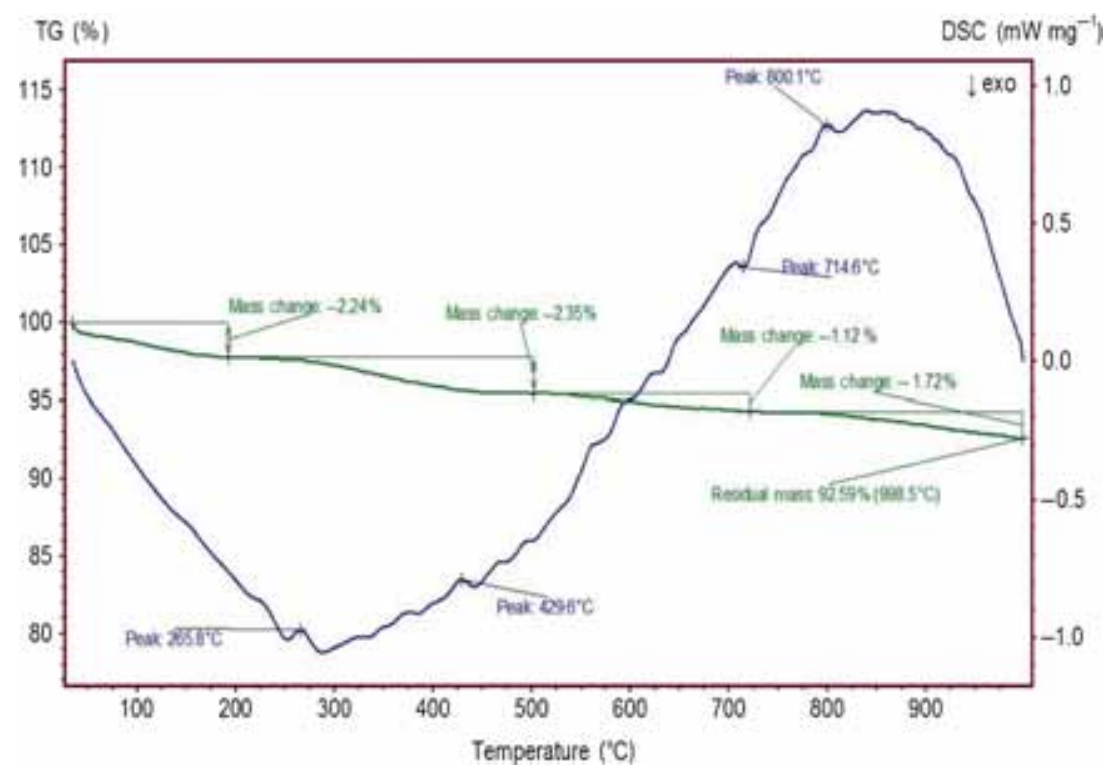

Figure 6. TG-DSC curves of the synthesized $\mathrm{Y}_{2} \mathrm{O}_{3}$ nanoparticles using Acalypha indica leaf extract.

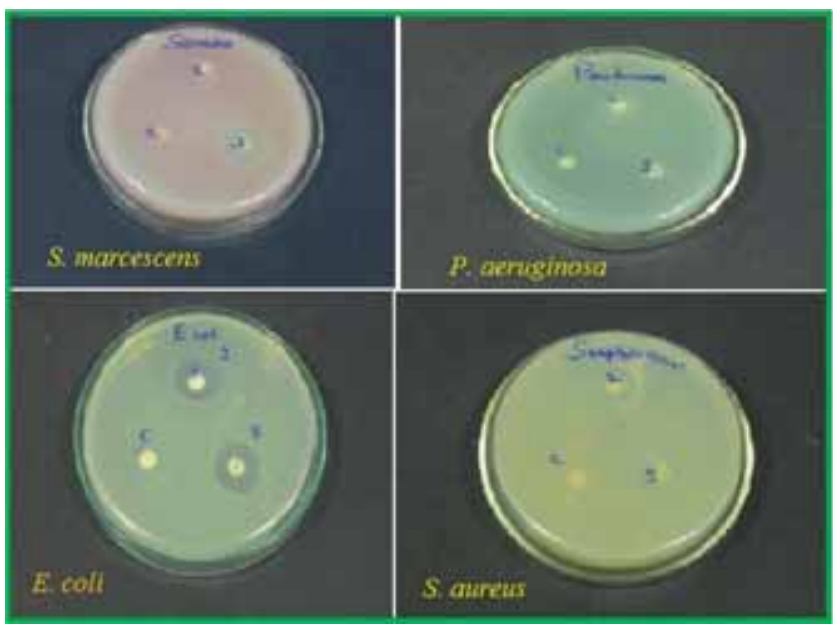

Figure 7. Antibacterial behaviour of the synthesized $\mathrm{Y}_{2} \mathrm{O}_{3}$ nanoparticles using Acalypha indica leaf extract.

In figure 6, the TGA/DSC plot acquired for the decomposition of the $\mathrm{Y}_{2} \mathrm{O}_{3}$ nanoparticle is presented. The sample was heated at a constant rate under $\mathrm{N}_{2}$ atmosphere with range of $35^{\circ} \mathrm{C} / 10.0\left(\mathrm{k} \mathrm{min}^{-1}\right) / 1000^{\circ} \mathrm{C}$. It is important to use an inert gas for performing such a study to avoid any premature oxidation and/or capping agent combustion. In TGA analysis, there is a gradual weight loss up to $200^{\circ} \mathrm{C}$ indicates that the removal of water molecules adsorbed on the nanoparticle and then slight increase of weight loss up to $700^{\circ} \mathrm{C}$ denotes the breakdown of the evaporation of physically and chemically adsorbed water and present in the nanoparticle. On further heating, no significant weight loss was observed supporting the crystallinity of particle takes place at $998^{\circ} \mathrm{C}$. In DSC analysis, a broad endothermic peak at $265^{\circ} \mathrm{C}$ indicates the evolving of water molecules. The curing temperature range from 429 to $714^{\circ} \mathrm{C}$ indicates the gradual removal of adsorbed water molecule on the $\mathrm{Y}_{2} \mathrm{O}_{3}$ nanoparticle. An exothermic peak at $800^{\circ} \mathrm{C}$, supports the formation of crystalline particles with phase-chemical purity. Based on these studies, the synthesized nanoparticles were thermally more stable. It was observed that the morphologies of nanoparticles can be controlled with the help of reaction methodology and type of solvents used.

\subsection{Antibacterial activity of $\mathrm{Y}_{2} \mathrm{O}_{3}$ nanoparticle}

The antibacterial activity of $\mathrm{Y}_{2} \mathrm{O}_{3}$ nanoparticle was examined against four representative microorganisms $S$. marcescens, $P$. aeruginosa, E. coli and $S$. aureus. $S$. marcescens is a common bacterium that can cause disease in humans and animals. It is found in soil, water, skin flora, and most man-made environments throughout the world. $P$. aeruginosa is involved in hospital acquired infections (HAIs), particularly catheter-associated bacteraemia, urinary tract infections and wound infection. E. coli, the most characterized bacterium, has been used as a model bacterial system for various antibacterial testing programs. $S$. aureus is responsible for the wide range of infectious diseases ranging from benign skin infections to life-threatening endocarditis and toxic shock syndrome. In a disc diffusion method, the $\mathrm{Y}_{2} \mathrm{O}_{3}$ nanoparticles laden disk has been prepared by keeping the disks in $5 \mathrm{ml}$ colloidal solutions of $\mathrm{Y}_{2} \mathrm{O}_{3}$ nanoparticles for 2 days. These disks absorb the $\mathrm{Y}_{2} \mathrm{O}_{3}$ nanoparticles and become dry and hence there is no presence of chloroform. Hence there is no impact of solvent to the bacteria. The plates with the disk were incubated at $35^{\circ} \mathrm{C}$ for $24 \mathrm{~h}$, after which the average diameter of the inhibition zone surrounding the disk was measured with a ruler. Figure 7 shows plates to which E. coli, P. aeruginosa, S. marcescens and $S$. 
aureus bacterial suspension were applied with nanoparticles laden disk and antibiotic impregnated disks. The diameter of inhibition zones around the disk containing $\mathrm{Y}_{2} \mathrm{O}_{3}$ nanoparticles in E. coli, P. aeruginosa, S. marcescens and S. aureus bacterial suspension are $11,10,10$ and $13 \mathrm{~mm}$, respectively.

The antibacterial effects of $\mathrm{Y}_{2} \mathrm{O}_{3}$ nanoparticles solutions can also be measured by determining the minimum concentration needed to inhibit the growth of tested microorganisms. Minimum inhibitory concentration (MIC) values of $\mathrm{Y}_{2} \mathrm{O}_{3}$ nanoparticles solutions against test microorganisms are given in table 1 . This shows that all tested microorganisms were completely inhibited at the concentration of 8-12 $\mu \mathrm{g} \mathrm{ml}^{-1}$ of $\mathrm{Y}_{2} \mathrm{O}_{3}$ nanoparticles. $\mathrm{Y}_{2} \mathrm{O}_{3}$ nanoparticles solution at the concentration of $8 \mu \mathrm{g} \mathrm{ml}^{-1}$ showed inhibition kinetics against $E$. coli and $P$. aeruginosa while $9 \mu \mathrm{g} \mathrm{ml} \mathrm{m}^{-1}$ of nano- $\mathrm{Y}_{2} \mathrm{O}_{3}$ was found to be the most effective against $S$. marcescens. The MIC of nano- $\mathrm{Y}_{2} \mathrm{O}_{3}$ against $S$. aureus was

Table 1. MIC of yttrium oxide nanoparticle solution against tested pathogens $\left(\mu \mathrm{g} \mathrm{ml}^{-1}\right)$.

E. coli P. aeruginosa S. marcescens S. aureus

\begin{tabular}{lllll}
\hline $\begin{array}{l}\text { MIC of nanosized } \\
\text { yttrium oxide }\end{array}$ & 8 & 8 & 9 & 14 \\
solution $\left(\mu \mathrm{g} \mathrm{ml}^{-1}\right)$ & & & & \\
\hline
\end{tabular}

also $14 \mu \mathrm{g} \mathrm{ml}^{-1}$. Thus, we can conclude from the results of this study that $\mathrm{Y}_{2} \mathrm{O}_{3}$ nanoparticles inhibited the growth and multiplication of all the tested microorganisms effectively.

Figure 8 shows the growth curves of E. coli, P. aeruginosa, $S$. marcescens and $S$. aureus in LB broth. The inhibitory effect of various concentrations of $\mathrm{Y}_{2} \mathrm{O}_{3}$ nanoparticles $(10$, $15,25,50,75$ and $100 \mu \mathrm{l}$ ) was examined through UV-visible spectrophotometer by taking optical density (OD) values. The growth rate of biomass was compared with the addition of $\mathrm{Y}_{2} \mathrm{O}_{3}$ nanoparticles with biomass. The growth rate of E. coli, $P$. aeruginosa, S. marcescens and $S$. aureus was decreased at the increased concentration of $\mathrm{Y}_{2} \mathrm{O}_{3}$ nanoparticles and the maximum inhibition of growth was obtained at $100 \mu \mathrm{l}$.

The mechanism of the bactericidal effect of $\mathrm{Y}_{2} \mathrm{O}_{3}$ nanoparticles is not very well-known. It is believed that cellular proteins become inactive after treatment with $\mathrm{Y}_{2} \mathrm{O}_{3}$ nanoparticles. It is also believed that $\mathrm{Y}_{2} \mathrm{O}_{3}$ nanoparticles after penetration into the bacteria have inactivated their enzymes, generating hydrogen peroxide and caused bacterial cell death. Heavy metals are toxic and react with proteins, therefore they bind protein molecules; as a result, cellular metabolism is inhibited causing death of the microorganism. Our experimental result shows that $\mathrm{Y}_{2} \mathrm{O}_{3}$ nanoparticles can be used as effective growth inhibitors in various microorganisms, making them applicable to diverse medical medicines and antimicrobial control systems.
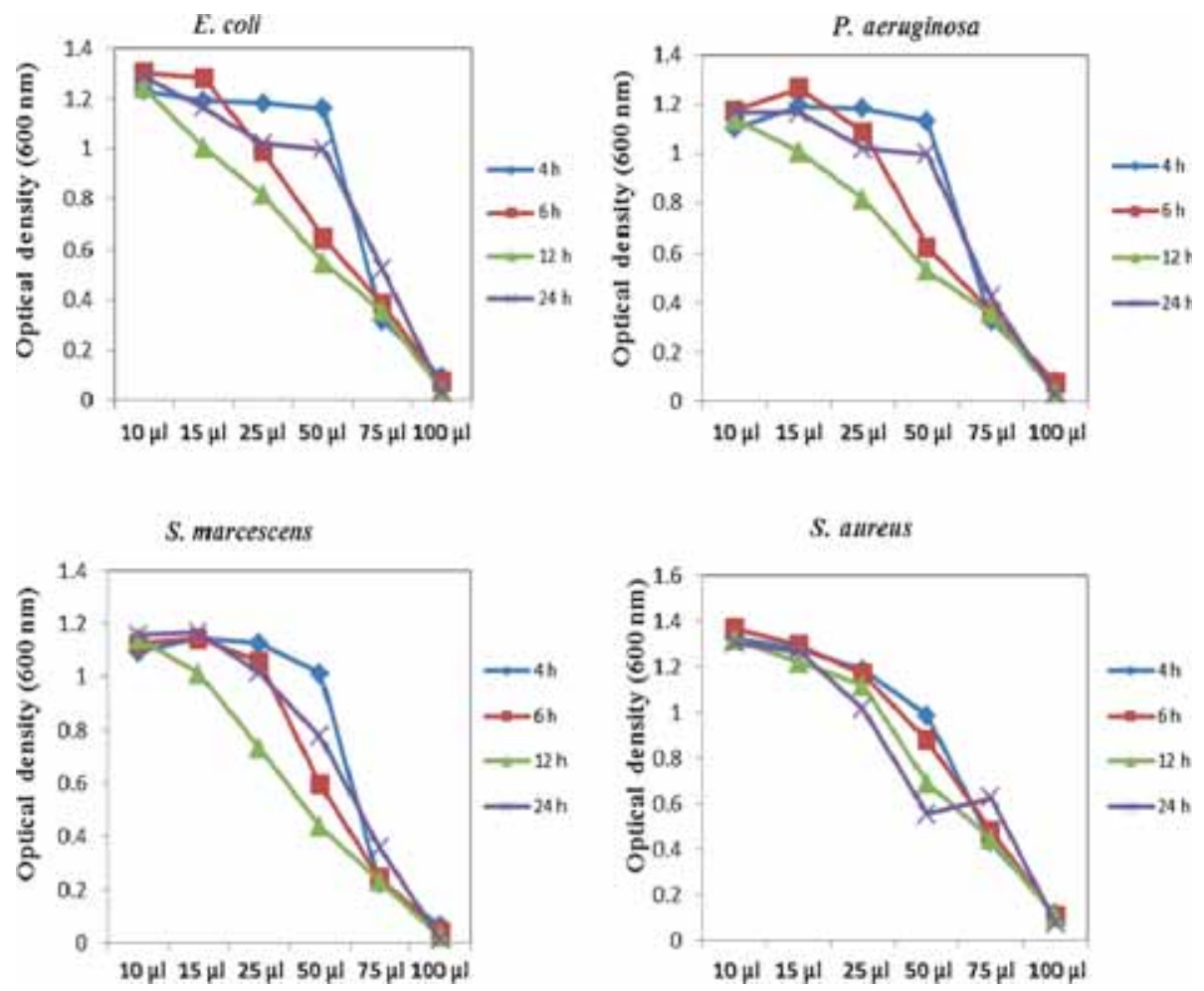

Figure 8. Growth curves of E. coli, P. aeruginosa, S. marcescens and S. aureus, LB broth containing various concentrations of the synthesized $\mathrm{Y}_{2} \mathrm{O}_{3}$ nanoparticles using Acalypha indica leaf extract. 


\section{Conclusion}

The present paper describes that the extract of $A$. indica leaf is capable of producing yttrium oxide nanoparticles from precursor material which are quite stable in solution. The authors proudly say that this is a first paper to describe the biosynthesis of $\mathrm{Y}_{2} \mathrm{O}_{3}$ nanoparticles. $\mathrm{Y}_{2} \mathrm{O}_{3}$ nanoparticles are much more stable upon treatment of thermal analysis and also it gives good antibacterial activity against the microorganisms such as $S$. marcescens, $P$. aeruginosa, E. coli and $S$. aureus. The achievement of such green synthesis of $\mathrm{Y}_{2} \mathrm{O}_{3}$ nanoparticle, contributes the rise of synthetic procedures using environmentally benign natural resources.

\section{Acknowledgement}

I gratefully acknowledge Dr M Anbu Kulandainathan and Dr K Kulangiappar, Scientist, Central Electrochemical Research Institute, Karaikudi, India, for their valuable suggestions during this part of my research work.

\section{References}

1. Martin C R 1994 Science 2661961

2. Mathur S, Shen H, Lecerf N, Kjekshus A, Fjellvag H and Goya G F 2002 Adv. Mater. 141405

3. Wu L, Yu L C, Zhang L, Wang X and Li S 2004 J. Solid State Chem. 1773666

4. Soppimath K S, Aminabhavi T M, Kulkarni A R and Rudzinski W E 2001 J. Control. Release 701

5. Kreuter J 2001 Adv. Drug Deliv. Rev. 4765

6. Hood J D, Bednarski M, Frausto R, Guccione S, Reisfeld R A, Xiang R and Cheresh D A 2002 Science 2962404
7. Mao H Q, Roy K, Troung-Le V L, Janes K A, Lin K Y, Wang Y, August J T and Leong K W 2001 J. Control. Release 70399

8. Chung Y I, Tae G and Yuk S H 2006 Biomaterials 272621

9. Gao X H, Cui Y Y, Levenson R M, Chung L W K and Nie S M 2004 Nat. Biotechnol. 22969

10. Akerman M E, Chan W C W, Laakkonen P, Bhatia S N and Ruoslahti E 2002 Proc. Natl. Acad. Sci. 9912617

11. Gao X H, Yang L L, Petros J A, Marshal F F, Simons J W and Nie S M 2005 Curr. Opin. Biotechnol. 1663

12. Roy I, Ohulchanskyy T Y, Pudavar H E, Bergey E J, Oseroff A R, Morgan J, Dougherty T J and Prasad P N 2003 J. Am. Chem. Soc. 1257860

13. Mornet S, Vasseur S, Grasset F and Duguet E 2004 J. Mater. Chem. 142161

14. Gardea-Torresdey J L, Parsons J G, Gomez E, Peralta-Videa J, Troiani H E and Santiago P 2002 Nano Lett. 2397

15. Gardea-Torresdey J L, Parsons J G, Gomez E, Peralta-Videa J and Troiani H E 2003 Langmuir 131357

16. Chandran S P, Chaudhary M, Pasricha R, Ahmad A and Sastry M 2006 Biotechnol. Prog. 22577

17. Huang J, Li Q, Sun D, Lu Y, Su Y and Yang X 2007 Nanobiotechnology 18105

18. Ankamwar B, Chinmay D, Absar A and Murali S 2005 J. Nanosci. Nanotechnol. 101665

19. Hirai T, Kawamura Y and Komasawa I 2004 J. Colloid Interface Sci. 275508

20. Verhiest K, Almazouzi A, Wispelaere N, Petrov R and Claessens S 2009 J. Nucl. Mater. 385308

21. Wang Z C and Kim K B 2008 Mater. Lett. 62425

22. Chang M L and Tie S L 2008 Nanotechnology 19075711

23. Andelman T, Gordonov S, Busto G, Moghe P V and Riman R E 2010 Nanoscale Res. Lett. 5263

24. Sathishkumar M, Sneha K, Won S W, Cho C W, Kim S and Yun Y S 2009 Colloids Surf. B 73332 